\title{
Hypercalciuria as a cause of persistent or recurrent haematuria
}

\author{
H STARK, M TIEDER, ${ }^{*}$ B EISENSTEIN, M DAVIDOVITS, AND A LITWIN \\ From the Paediatric Nephrology Units, Beilinson Medical Center, Petah Tiqva, and *Assaf Harofeh Hospital, \\ Zerifin, and the Sackler School of Medicine, Tel Aviv University, Israel
}

\begin{abstract}
SUMMARY Of 91 children with idiopathic persistent or recurrent haematuria, eight also had hypercalciuria. This was transient in three and persistent in five. Persistent hypercalciuria was a rare cause of microscopic haematuria (two of 80 ), but common in association with gross haematuria (three of 11).
\end{abstract}

Hypercalciuria has been reported as causing haematuria, both gross and microscopic, in the absence of diagnosable calculi. ${ }^{1-5}$ Stapleton $e t a l^{5}$ described 23 cases of hypercalciuria in 83 children being investigated for idiopathic haematuria (microscopic and macroscopic) over a two year period. In 23 children a renal or urological cause was found; 22 of the remaining 60 children had hypercalciuria. Of 37 children with gross haematuria, 16 had hypercalciuria. As these findings do not accord with our experience, we report a series of 91 patients.

\section{Patients and methods}

During the period $1979-85$ we saw 91 children aged from 2 to 15 years with persistent or recurrent haematuria in whom no renal or urological cause could be found. Kidney biopsies were not performed. Patients who had protein in the urine were excluded, as were those with other diseases or with a previous history of stones in the renal tract. Forty children were seen at the Assaf Harofeh Hospital and 51 at the Beilinson Medical Centre. Eleven patients (six and five at the two hospitals, respectively) had at some time had gross haematuria.

A 24 hour urine specimen was obtained from all patients under normal home conditions and without dietary modification. Hypercalciuria was diagnosed as a calcium:creatinine ratio of over $0 \cdot 6: 1$, this representing the ninety eighth centile calculated for 131 healthy children studied by one of us (M Tieder, unpublished observation). This reflected a calcium excretion of greater than $0.1 \mathrm{mmol} / \mathrm{kg} / 24$ hours. Whenever a value of greater than 0.6 was found at least two further urine collections were obtained.

The concentrations of calcium and creatinine in the urine were measured by the Technicon autoanalyser at the Beilinson Medical Center. At the
Assaf Harofeh Hospital, the calcium concentration was measured manually by atomic absorption spectrophotometry and the creatinine concentration by the alkaline picrate reaction. In six urine specimens examined in both laboratories, concentrations of calcium and creatinine, and the calcium:creatinine ratio were almost identical, the mean (SD) difference in calcium:creatinine ratio being $0.04(0.02)$.

\section{Results}

Eight of the 91 patients with haematuria also had hypercalciuria on a single estimation. Repeat urine collections confirmed persistent hypercalciuria in only five of these children, in three calcium excretion having returned to normal. Three of the patients with hypercalciuria had gross haematuria at some time, and two of the three later developed renal calculi. The remaining patients have been followed up on treatment for two to six years, and have not developed calculi. All five of these children have at least one parent with hypercalciuria.

Mean (SD) calcium:creatinine ratio in the urine of the 83 patients who did not have hypercalciuria measured from a single urine collection, was 0.25 $(0 \cdot 17)$ compared with $0 \cdot 28(0 \cdot 17)$ in 131 healthy children. Thus haematuria does not seem to be associated with higher calcium excretion except in those subjects with pronounced hypercalciuria.

\section{Discussion}

In our series about $9 \%$ of the children with persistent or recurrent haematuria had hypercalciuria (that is, a calcium:creatinine ratio more than two standard deviations above the mean for our healthy childhood population) when a single 24 hour urine specimen was tested. It is difficult to explain the difference between these findings and those of Stapleton et al ${ }^{5}$ who found hypercalciuria in $37 \%$ of all children with unexplained haematuria and in $15 \%$ of those with microscopic haematuria. The authors of that paper believe that urolithiasis is more prevalent in their population than in other regions. Unfortunately they did not compare calcium excretion in the urine of children with haematuria with that of normal children, and they 
diagnosed hypercalciuria on the results of testing a single urine collection. We believe it is important to record persistent hypercalciuria by testing repeated urine collections, as a single collection may be misleading.

The fact that two of our five hypercalciuric patients (both of whom had had episodes of gross haematuria) went on to develop calculi suggests that such patients should be treated. As idiopathic hypercalciuria is a lifelong, usually asymptomatic condition such treatment should probably be limited to recommending a diet low in calcium and ensuring that even patients who have never shown any evidence of stones in the renal tract should drink enough fluid.

\section{References}

1 Roy S III, Stapleton FB, Noe HN, Jerkins, G. Hematuria preceding renal calculus formation in children with hypercalciuria. J Pediatr 1981;99:712-5.

2 Kalia A, Travis LB, Brouhard BH. The association of idiopathic hypercalciuria and asymptomatic gross hematuria in children. J Pediatr 1981;99:716-9.

${ }^{3}$ Moore ES. Hypercalciuria in children. In: Berlyne GM, ed. Contributions to nephrology. New York: Karger, 1981:20-32.

${ }^{4}$ Hymes LC, Warshaw BC. Idiopathic hypercalciuria. Renal and absorptive subtypes in children. Am J Dis Child 1984;138: 176-80.

${ }^{5}$ Stapleton FB, Roy S III, Noe HN, Jerkins G. Hypercalciuria in children with hematuria. $N$ Engl J Med 1984;310:1345-8.

Correspondence to Dr H Stark, Paediatric Nephrology Unit, Beilinson Medical Centre, Petah Tiqva, 49100, Isreal.

Accepted 27 July 1987

\title{
Pulmonary interstitial emphysema: selective bronchial occlusion with a Swan-Ganz catheter
}

\author{
S LEWIS, E PELAUSA, C OJAH, AND B PAES
}

Division of Neonatology, Department of Paediatrics, McMaster University Health Sciences Centre, Chedoke-McMaster Hospital, Hamilton, Canada

SUMMARY A 26 week preterm infant ventilated for hyaline membrane disease developed severe pulmonary interstitial emphysema with extensive right sided bullous formation, mediastinal shift, and subsequent left sided atelectasis. A paediatric SwanGanz catheter was used for selective bronchial occlusion with dramatic improvement in the infant's clinical condition and radiographic findings.

Pulmonary interstitial emphysema (PIE) occurs as a complication of mechanical ventilation in infants with underlying hyaline membrane disease. The use of high peak ventilatory pressures with resultant barotrauma leads to extrapulmonary effusions of air along peribronchovascular, pleural, and interlobular passages from ruptured alveoli. ${ }^{1}$ The morbidity from the presence of such interstitial gaseous blebs stems largely from hypoxia secondary to a ventilation/perfusion imbalance in an already compromised infant. Accumulation of unilateral interstitial air may also result in bullous air pockets with eventual mediastinal shift and compression of the contralateral lung.

We report our experience with selective bronchial occlusion of the right mainstem bronchus with a Swan-Ganz catheter in a preterm infant with life threatening complications of PIE.

\section{Case report}

A girl weighing $760 \mathrm{~g}$ was born at 26 weeks' gestation by a vaginal breech delivery with an Apgar score of 5 and 6 at one and five minutes, respectively. The baby required mechanical ventilation almost immediately for moderately severe hyaline membrane disease (inspiratory pressures $14 / 3 \mathrm{~cm}$ $\mathrm{H}_{2} \mathrm{O}$; fractional inspiratory oxygen $\left.\left(\mathrm{FiO}_{2}\right) 1 \cdot 0\right)$. The initial chest radiograph taken five hours after birth showed early signs of bilateral PIE. At 12 hours of age a right pneumothorax occurred and was drained. Further deterioration in oxygenation necessitated increased ventilation (pressures $22 / 2 \mathrm{~cm}$ $\mathrm{H}_{2} \mathrm{O} ; \mathrm{FiO}_{2} 1 \cdot 0$ ). Ventilator support remained unchanged until day 16 , when radiographs indicated a worsening PIE that was associated with further hypoxaemia. Stabilisation proved difficult with recurrence of a right pneumothorax after increasing ventilatory pressures to $37 / 2 \mathrm{~cm} \mathrm{H}_{2} \mathrm{O} ; \mathrm{FiO}_{2} 0 \cdot 8$. Despite dependent positioning of the right emphysematous lung and carefully monitored ventilation, the infant continued to deteriorate.

On day 18 selective intubation of the left mainstem bronchus under fluoroscopy was unsuccessful. The radiographic findings (fig 1) showed large cystic lucencies with hyperaeration and a persistent herniation of the right lung across the midline with mediastinal displacement to the left. At this time the 